Cad.Est.Ling., Campinas, 47(1) e (2):99-107, 2005

\title{
NOTAS SOBRE O NOME PRÓPRIO NA AQUISIÇÃO DA ESCRITA
}

\author{
ZELMA R. BOSCO \\ (CEFIEL, Universidade Estadual de Campinas \\ Grupo de Pesquisa em Aquisição da Linguagem)
}

\begin{abstract}
This paper proposes a reflection on the writings composed by letters of the child's own name. It seems that fragments composed by the child's own name show its writing constitution as an effect of the language. We entend to point out the necessity for discussing the statute of the proper name based on the relation between the child and its writing. These writings were produced by children aged 4 to 5 years.
\end{abstract}

Os estudos na área de aquisição da linguagem escrita são, há muito tempo, atravessados pela questão da escrita do próprio nome nas produções gráficas infantis. Hildreth (1936), Lurçat (1974), Ferreiro \& Teberosky (1979), Ferreiro (1987) e Teberosky (1991), entre outros no campo da psicologia, reconhecem a precocidade da tendência infantil em escrever o próprio nome nas produções gráficas, sobretudo os desenhos. Na realização desse escrito pela criança seria possível verificar o surgimento de elementos não figurativos que poderiam ser interpretados como tentativas de escrita do nome, mas que não possuiriam relação com a pauta sonora. A função desse escrito seria identificar as produções infantis, o que, na escola, adquire grande importância.

Desde nosso trabalho de 1999, "No jogo dos significantes, a infância da letra", a escrita do nome colocou-se como locus privilegiado em nossas discussões sobre as relações entre desenho e escrita. Esse privilégio deveu-se, em princípio, ao fato de termos reconhecido esse escrito como sendo, inicialmente, o único texto solicitado pela professora e produzido individualmente pela criança em sala de aula, independente da série freqüentada na préescola cujos trabalhos acompanhamos por um período de três anos.

Além disso, vale dizer que é grande a expectativa que envolve a escrita do nome pela criança, que significa, aos olhos dos pais e da escola, o primeiro triunfo da criança nas letras. Em função disso, grande ênfase é colocada pela escola em busca de viabilizar essa escrita.

Nas salas de aula da pré-escola mencionada, um painel com os nomes de todas as crianças ao lado de suas respectivas fotografias é fixado para poder ser contemplado por elas e funcionar como fonte de consulta para a escrita do nome da criança e de seus amigos. Um cartão individual com o nome escrito é fornecido a cada criança e sempre está acessível a ela. Além disso, todo o material escolar tem o nome da criança grafado.

Nas atividades escolares diárias, cada dia uma criança tem seu nome escrito pela professora na lousa, durante a brincadeira de escolha do ajudante da professora naquele 
dia. O nome do ajudante sorteado tem suas letras identificadas e contadas uma a uma e, muitas vezes, a quantidade de letras desse nome é revelada pela professora como "pista" para a descoberta do nome do ajudante escolhido.

À medida em que a descoberta do nome desse ajudante se torna "fácil" para as crianças, a professora, buscando prolongar essa brincadeira, embaralha as letras desse nome na lousa e as dispõe não linearmente. Nesse momento, as semelhanças e as diferenças dessas letras com outras de outros nomes de crianças da turma são identificadas pela professora. Além disso, ao final de cada atividade escolar realizada pela criança é solicitado a ela que escreva o seu nome, sempre no verso da folha, já que a frente desta é o lugar que a professora dispõe como sendo do desenho.

É nesse contexto que a escrita do nome vai se constituindo. Os traços rabiscados sobre o papel, aos poucos, vão ganhando corpo e forma até o surgimento de letras que pertencem ao nome da criança. A seqüência de letras que é escrita pela criança, atendendo ao pedido da professora para que se identifique em seus trabalhos, não é estável: a quantidade de seus elementos, sua posição na série escrita e sua linearidade na folha de papel vão tendo sua estabilidade alcançada aos poucos.

Ao mesmo tempo em que as letras do nome ganham corpo e passam a compor o fragmento que se lê como nome da criança em sua produção escrita, essas mesmas letras vão surgir como elementos constitutivos de verdadeiras montagens textuais em resposta ao pedido por produções escritas, sejam elas meras etiquetas de objetos desenhados, histórias contadas por escrito pelas crianças e até mesmo cópias ou ditados realizados pela professora, quando supostamente a relação entre o oral e o escrito é colocada em jogo.

Para situar nossas colocações trazemos alguns episódios de realização escrita de crianças. Destacamos, num primeiro momento, as produções de Guilherme Luís (GL), realizadas na faixa etária entre 4 e 5 anos. Observamos que, ao mesmo tempo em que seu nome está ganhando forma, linearidade e seqüencialidade, as letras com as quais GL compõe as etiquetas que acompanham os desenhos são, também, letras de seu nome, formando combinações inusitadas e preenchendo o espaço da escrita que lhe é solicitada.

As outras letras que aos poucos vão sendo incorporadas na escrita dessa criança parecem ser efeito de relações de semelhança e dessemelhança estabelecidas entre as letras do nome com as outras letras dos textos escritos pelos quais a criança circula. A relação das letras do nome com esses textos parece propiciar, pela ressignificação mútua, a emergência de outras letras na escrita da criança.

Vamos nos deter em uma tarefa de cópia de GL, após ter realizado as produções escritas mencionadas, quando este contava com 5 anos e cursava o primeiro semestre do Jardim. A instrução passada para ele era de que realizasse a cópia do nome de sua mãe, a partir da escrita em letra de forma realizada pela professora. GL já havia escrito espontaneamente, em outro momento, o nome de sua mãe, etiquetando um desenho que fizera. Neste desenho, ele e sua mãe aparecem juntos, e ao lado do desenho da mãe GL escreve o bloco "ZMEAI" para "ZELMA", com a primeira letra "espelhada". Note-se que, se nessa seqüência grafada é possível reconhecer as letras que compõem o nome de sua mãe, a última letra da escrita deste nome por GL - "I" - , porém, não faz parte do nome da mãe. 
Cadernos de Estudos Lingüísticos 47(1) e (2) - Jan./Dez. 2005

Retomando a tarefa de cópia mencionada, nela verificamos na escrita do nome da mãe empreendida por GL os seguintes elementos: "ZMERIL", novamente com a primeira letra - "Z" - "espelhada". Apesar de se tratar de cópia, a escrita que emerge preenchendo o lugar do nome da mãe revela-se um misto de letras do nome dela com letras do nome da criança. Se "Z" é realmente a primeira letra do nome da mãe, "M" e "E" são letras que, além do nome da mãe, fazem parte também da escrita do nome da criança. Assim, em determinado momento da cópia do nome da mãe por GL, parece incidir um processo associativo, que permite colocar em relação os elementos que a criança recorta do nome da mãe com as letras de seu próprio nome, constituindo a metáfora.

Num movimento metonímico um deslocamento se dá, promovendo como efeito o deslizamento dessa escrita para as letras do nome da criança; deslizamento este que a criança ignora e não estranha. O bloco que emerge como escrita do nome da mãe apresentase, então, como uma espécie paradoxal, um misto que não se constitui propriamente nem como nome da mãe, nem como nome da criança, embora, enfatizamos, o que se pretendia na realização da tarefa fosse uma cópia, o que, para certos estudiosos da escrita infantil, é somente "desenho de letras e não escrita" (Ferreiro, 1987:103).

Apesar de nesse momento os escritos de Guilherme não se apresentarem da maneira como prevê a língua constituída, ao reconhecer a seqüência grafada como escrita do nome ou de qualquer outro texto, o adulto, como instância do Outro, sanciona aquele jogo de letras como escrita. Essa autenticação faz-se em função da antecipação que se produz naquele que lê. Ao identificar-se e identificar aquela criança como um semelhante, o adulto antecipa naquele jogo de letras a escrita de um sujeito.

Esbarramos, então, na diferença entre a expressão gráfica e sua interpretação, que nos permite reconhecer a indeterminação sintática, semântica e pragmática das primeiras realizações textuais escritas. Ao mesmo tempo, coloca em evidência o papel do outro ao interpretar, ao ancorar os fragmentos escritos pela criança em textos, fazendo-os passar novamente, como diz Cláudia Lemos, pelo "moinho da linguagem, ou pelo Outro, tesouro dos significantes" (Lemos, 2001:48)

A escrita com as letras do nome aponta, portanto, para duas relações distintas: por um lado, a existência de uma escrita que adquire legibilidade pela antecipação do nome da criança nos fragmentos por ela grafados. Essa possibilidade de leitura parece, em princípio, não depender nem da quantidade dos elementos grafados, nem da (des)organização destes na seqüência escrita. Entendemos, então, que a legibilidade desse escrito não se sustenta nos segmentos de letras tomados em si, mas advém como efeito da montagem textual, da relação que se estabelece entre os elementos da cadeia.

Por outro lado, da fragmentação constante do nome da criança, configurando um processo contínuo de desmontagem do nome, resulta uma escrita que resiste à leitura, por não apontar para uma relação de fonetização com a oralidade, e não haver, de imediato, nada que permita sustentar uma possibilidade de leitura "termo a termo" sugerida pela escrita alfabética.

Lembramos aqui que, quando esta escrita com as letras do nome preenche o espaço da folha destinado à assinatura, não há dúvidas para aqueles que cercam a criança sobre o fato de ali estar escrito o nome dela: tanto a criança, como a professora, a mãe e as outras crianças do grupo ignoram sua (des)organização e quantidade de elementos grafados ao 
ler. Mas, a leitura do escrito fica impedida quando as letras do nome da criança preenchem o espaço da escrita de outros textos - etiquetas, histórias escritas, ditados, dentre outros , embora a criança que o escreveu não estranhe e, quando solicitada, realize uma certa leitura do texto.

Em princípio, essa escrita com as letras do nome é aceita como escrita da criança. Mas, aos poucos, passa-se a exigir dela uma outra maneira de escrever. Nesse sentido, o episódio de Thomas Artur (THO-1), a seguir, é revelador.

A instrução passada pela professora para a realização dessa tarefa era de que a criança procurasse em revistas figuras de objetos, cujos nomes iniciassem com a primeira letra do nome da criança, no caso de Thomas Artur, a letra "T". Thomas Artur, realizando, de início, corretamente sua tarefa, recorta e cola, logo abaixo da escrita de seu nome, as seguintes figuras: touro, torneira, tomate, toalha e troféu, sendo esta última figura colada um pouco mais acima na folha, embaixo da escrita da letra "S" de seu nome. Em seguida, etiqueta essas figuras com o nome dos objetos que elas representam, com exceção da figura do tomate, por esquecimento, talvez. As etiquetas são todas escritas com letras de seu nome: THMSA, HOOMAS, MOO e SOAS, respectivamente (Fig. THO-1).

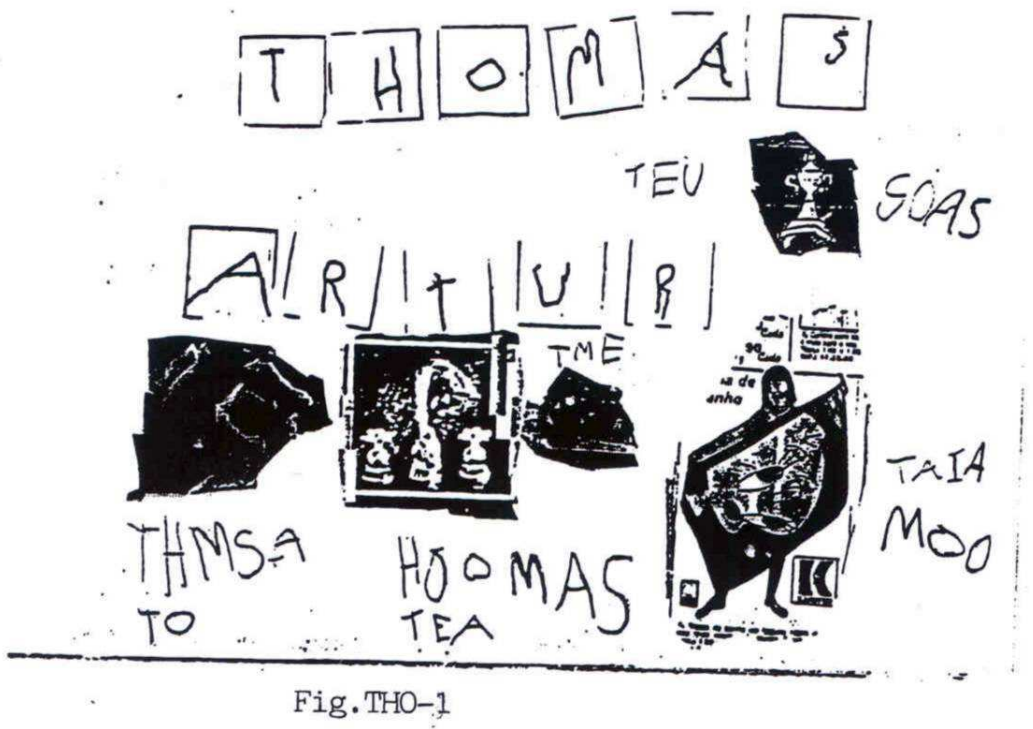

A professora, inconformada com essa escrita, uma vez que Thomas Artur já realiza uma escrita, a seu ver, silábica, chama a criança em um canto da sala e diz a ela que não quer "essa escrita", mas "a outra", silabicamente constituída e que, segundo a professora, a criança já é capaz de realizar. Senta-se junto com Thomas e começa a silabar, palavra por palavra, e ele escreve, próximo dos blocos anteriormente escritos com as letras do nome, 
Cadernos de Estudos Lingüísticos 47(1) e (2) - Jan./Dez. 2005

TO para "touro", TEA para "torneira", TME para "tomate", TAIA para "toalha" e TEU para "troféu" (Fig. THO-1). E temos, então, a realização escrita almejada pela professora, com indícios de fonetização. Note-se que, apesar de ser capaz de realizar, segundo a professora, uma escrita dita silábica, esta escrita só emerge na realização da tarefa solicitada como efeito da silabação promovida pela professora.

Enfatizamos que os elementos que são recortados dos textos pelos quais a criança circula, nesse momento de sua relação com a linguagem, são letras do seu nome. Assim, uma discussão impõe-se: o estatuto da escrita do próprio nome no percurso da relação da criança com a escrita.

Uma discussão nesse sentido faz-se notar já no trabalho de Calil, sob a ótica da Análise do discurso. Ao analisar um momento da escolha do nome dos personagens de uma história inventada por duas meninas, o autor toca na questão da historicidade do nome próprio, que se faz e refaz na medida em que se singulariza como nome de alguém. Para Calil, o nome próprio em si não tem sentido, "é puro significante" (Calil, 1995: 151).

A presença das letras do nome da criança articulando-se de forma variada, compondo o texto infantil também foi verificada por Mota (1995) nas produções escritas de crianças na faixa etária entre 6 e 9 anos, em uma sala de alfabetização em que se privilegiavam leitura e produção de textos. Para a autora, a aparente análise do nome pela criança, a insistência das letras do nome, que se compõem e se recompõem ao longo do texto da criança "não significa mais do que um uso das mesmas". E reconhece que, como "significantes que lhe foram fornecidos pela professora", "marcarão, de modo especial, o acesso dessa criança à escrita” (Mota, 1995:144).

Mota observa, ao longo das transformações da relação da criança com a escrita, a interferência, a insistência de certos significantes que funcionariam como marcas em sua escrita. Dentre eles, a autora identifica o nome da própria criança. Ao entrar em relação com significantes subtraídos de outros "textos-matriz", estes representados pelos textos escritos que circulam em sala de aula, o nome da criança, ou seus fragmentos, possibilita a ressignificação do que ela escreveu.

As combinatórias de letras presentes nas produções infantis são vistas pela autora como acontecimentos e remetem aos textos com os quais a criança entrou em relação, mas há diferença. Os fragmentos que a criança usa são versões de fragmentos dos textos-matriz, com os quais ela recorta e costura seqüências variadas. Dentre eles, o seu próprio nome pode emergir como o significante que rege toda a composição gráfica.

A autora identifica a presença das letras do nome constituindo outros textos na escrita infantil e reconhece que estas letras, como já citamos, "marcarão, de modo especial, o acesso dessa criança à escrita" (Mota, 1995). No entanto, seus dados permitem reconhecer a entrada de fragmentos do nome na composição dos textos escritos pela criança como efeito da contingência.

Os episódios por nós analisados, em princípio, possibilita-nos identificar o nome da criança, funcionando como uma marca, que produz como efeito a abertura para uma nova escrita. Essa marca abre caminho para o surgimento de outras, propiciando, pela interpretação e ressignificação mútua, o início de uma série, revelando o engajamento do sujeito de um modo particular num saber e, ao mesmo tempo, fazendo-o sujeito de seus 
próprios significantes. Nesse sentido, entendemos que a escrita do nome possibilitou uma inscrição simbólica que marcou um real, produzindo efeitos.

Lembramos que não é qualquer escrita que aqui focalizamos, mas a escrita do nome da criança, significante em que ela se reconhece e é reconhecida como sujeito de sua própria escrita. A singularidade da escrita em questão convoca uma discussão sobre o nome próprio, investido na escrita do nome.

E uma discussão sobre a questão do nome próprio está longe de ser objeto de consenso entre aqueles que sobre ele se indagam. De todos os objetos de estudos da linguagem, o nome próprio inspira discussões em domínios de conhecimento variados e exteriores à lingüística: a filosofia, a lógica, a semiologia, a antropologia, a psicanálise, dentre outros.

Por apontar diretamente para o indivíduo que ele nomeia, o nome próprio parece representar uma passagem segura entre linguagem e mundo. Mas, longe da aparente tranqüilidade dessa relação, encontramos a dificuldade em analisá-la lingüisticamente.

E se a discussão é sobre o estatuto lingüístico do nome próprio, não podemos deixar de lado uma consulta ao Curso de Lingüística Geral (CLG). Ao fazê-la , verificamos que Saussure se cala sobre possíveis questões que o nome próprio suscita. Uma alusão a seu respeito é feita no capítulo V, da Parte III, sobre "Analogia e Evolução", não sendo retomada em nenhuma outra parte do CLG.

Ali, o nome próprio é declarado palavra isolada que não permite nenhuma análise no interior do sistema. Nas palavras de Saussure, "as únicas formas sobre as quais a analogia não tem poder nenhum são naturalmente as palavras isoladas, tais como os nomes próprios, especialmente os nomes de lugares (cf. Paris, Genève, Agen etc.), que não permitem nenhuma análise e por conseguinte nenhuma interpretação de seus elementos; nenhuma criação concorrente surgiu a par deles" (Saussure, 1974:201, destaques no original).

Não podemos, no entanto, negar a preocupação de Saussure com a questão do nome próprio e esta será detectada fora do CLG. Nos Cahiers, produzidos entre 1906 e 1909, Saussure entrega-se a verdadeiros exercícios de decifração na tentativa de obter a chave dos versos saturninos, a qual, para o autor, passa necessariamente por um vocábulo isolado; vocábulo que se relaciona com o destinatário ou com o assunto da passagem.

Nesses versos, a presença do nome próprio como "palavra-tema", cujo material o poeta atualiza na composição dos versos, revelar-se-á inevitável como princípio gerador do texto, em que "um verso ( ou mais) anagramatizam uma única palavra (em geral um nome próprio, o de um deus ou de um herói)" (Starobinski, 1974: 22). Note-se que, para Saussure, os anagramas não são vistos como um jogo acessório da versificação, mas "eles se tornam a base, quer o versificador queira ou não [...] Fazer versos com anagrama é, forçosamente, fazer versos segundo o anagrama sob o domínio do anagrama" (Saussure, Ms.fr.3963, apud Starobinski, 1974:23)

É interessante notar que o nome próprio ganha destaque nas reflexões saussureanas quando o autor trata de um texto específico: a poesia, lugar em que não se pode deixar de lado o "ponto de cessação da falta de se escrever" a que se refere Milner. Esse "ponto de cessação", também chamado pelo autor de "ponto de poesia", "para uns é a morte, para outros o obsceno, ou ainda o sentido mais puro que se atinge arrancando as palavras do círculo da referência ordinária - o que se designa como hermetismo" (Milner, 1987:25). 
Cadernos de Estudos Lingüísticos 47(1) e (2) - Jan./Dez. 2005

A poesia ocupa um lugar que se define por não ignorar o "ponto de cessação" e a ele, constantemente, retornar; e é justamente isso que a lingüística, assim como a gramática, não deve levar em conta. Tal como é configurada no discurso da ciência, a língua deve ser apreendida como uma completude e, por isso, não deve comportar nenhuma falta, nenhuma margem para equívocos. Por essa perspectiva, a língua adquire uma totalidade própria do imaginário.

Mas, na língua só há equívocos, e para designar em toda língua o registro que a destina ao equívoco, Milner toma emprestado de Lacan o termo lalangue (alíngua), em que reconhece uma dimensão da própria língua que vai além de sua suposta unidade. Lalangue (alíngua) designa, então, em toda língua o registro que a destina ao equívoco.

Considerar lalangue (alíngua) é, segundo Milner, supor a possibilidade do equívoco no funcionamento da língua, produzindo fissuras, deslocamentos, rompimentos, num relançar constante de sentidos, que ganham maior visibilidade na poesia, no ato falho, no chiste. Significa, ainda segundo Milner, incluir aquilo pelo qual, "de um único e mesmo movimento, existe língua (ou seres qualificáveis de falantes, o que dá no mesmo) e existe inconsciente" (op.cit.:17-18). Na lalangue (alíngua) acontece de um sujeito imprimir uma marca e abrir uma via onde se escreve o impossível de se escrever.

Em seu livro "O amor da língua", Milner identifica lalangue (alíngua) como o registro que permite distinguir uma língua de qualquer outra, impedindo, por incomensurabilidade, a formação de uma classe de línguas que a inclua; "dito de outra maneira, alíngua é o que faz com que uma língua não seja comparável a nenhuma outra"(op.cit.: 15).

Em suas reflexões, o autor reconhece a língua materna como do domínio da poesia e a identifica como a figuração mais perfeita da lalangue (alíngua). A questão da língua materna encontra, por essa perspectiva, um estatuto singular, um caráter distintivo que a impede de fazer número com outras línguas - ela é única e distinta entre as línguas.

É no campo da relação entre língua e lalangue (alíngua) que Pereira de Castro considera que o conceito de língua materna pode contribuir nas reflexões sobre aquisição de linguagem, por permitir mostrar "que o excesso, a heterogeneidade, a singularidade da fala da criança, são da natureza do não-um, mas que devem ser tratados como uma dimensão da própria língua e não como fora de sua ordem, como fatores extralingüísticos. Nem na esfera do biológico, nem na do psicológico ou do social" (Pereira de Castro, 1998: 253).

Por essa perspectiva, segundo a autora, coloca-se em questão um ponto de articulação entre o desejo inconsciente e a língua, que, para Milner, é o lugar em que se inscreve o sujeito da linguagem. Trata-se, então, segundo Pereira de Castro, de considerar na aquisição de linguagem uma articulação significante, ou seja, um lugar onde um sujeito significa. Tomada como "esta experiência inaugural e definitiva, isto é, a passagem do lugar de infans ao de ser de linguagem, a aquisição da língua materna é a figuração deste ponto em que a língua vai significar a criança, vai marcá-la por um modo de funcionamento, com o perfil de um ser falante, isto é, sempre dividido entre as posições de ser falado pela e ser autor de seus enunciados" (op.cit.: 254).

A caracterização que Pereira de Castro busca dar à língua materna passa por tomar "o silêncio como metáfora do momento em que a criança ainda não fala para, a partir dele, desenhar uma experiência inaugural, uma articulação significante do sujeito na língua". A 
língua materna, que ocupa cada um de nós, como vimos, não faz número com as outras línguas. "Por essa particularidade, por ser uma experiência estruturante e única, ela é também inesquecível, não silenciável", afirma Pereira de Castro, "mesmo quando a julgamos perdida, esquecida; mesmo, enfim, quando não podemos reconhecê-la na superfície da fala" (op.cit.: 255)

Nesse sentido, pode-se afirmar que o caráter estruturante da língua materna faz com que a passagem por ela conduza a uma mudança de posição subjetiva, resultante da "captura" (cf. Lemos, 1992, 1997) de um corpo para a condição de sujeito. Aí, o nome próprio, que nomeia um sujeito em sua língua materna, vem marcar a fundação dessa posição subjetiva.

Ao nascer, o bebê humano surge como um corpo que permitirá o nascimento de um sujeito. Este, contudo, só-depois nascerá como sujeito para si, para o mundo e para os outros. Mas, mesmo antes da existência desse corpo, um sujeito já adquire sua potencialidade virtual, simplesmente porque há linguagem: há conversas, falas, imaginários e mitos particulares que antecipam a existência desse feto como um sujeito.

O nome próprio atribuído a essa criança ainda por existir desencadeia entre os membros da família a criação de fantasias, constituindo um imaginário que, mesmo na ausência física da criança, já organiza a vida desse feto já-feito sujeito. Neste imaginário, um nome próprio possibilita o investimento desse feto, antecipando nele um bebê, interpretando-o como um sujeito articulado numa história narrativa familiar que o sustenta.

O nome, então, encarna um sujeito e funde-se a ele ao ponto de tornar-se o próprio sujeito. O gesto simbólico da nomeação permite a significação e, ao mesmo tempo, o alçamento de um corpo biológico à condição de sujeito. É nesse sentido que Pereira de Castro afirma que a nomeação é "fundadora: designa o corpo por um nome, abrindo-lhe um destino subjetivo" (Pereira de Castro, 2003: 49).

O caráter único, distintivo e estruturante da língua materna parece transferir-se para o nome próprio: não se pode renunciar a ele, esquecê-lo; é exclusivo, já que a homonímia em jogo nos nomes não retira a singularidade de um nome como sendo de um sujeito; é, em princípio, imutável, e na tradução de uma língua para outra mantém inalterada sua estrutura lítero-sonora. O nome próprio, enfim, embora possa se relacionar com outros significantes, não aceita sinonímia ou paráfrase, o que o localiza com um traço distintivo.

O caráter do nome próprio alça-o a um lugar singular nas reflexões sobre a aquisição da linguagem. Nosso trabalho busca reconhecer esse estatuto singular no que se refere à escrita do próprio nome, uma vez que, escrever o nome sobre o papel resulta na realização de uma marca em que o nome próprio está investido. O nome escrito mostra-se, portanto, como um espelho em que o sujeito se reflete, se absorve e se reconhece. É, principalmente, o significante com o qual o sujeito se identifica e é identificado.

É nesse sentido que buscamos encaminhar nossas reflexões. Os episódios por nós apresentados possibilita-nos, em princípio, indagar acerca do caráter fragmentário da escrita da criança nesse momento do percurso de sua relação com a escrita, sem reduzirmos essa discussão às restrições de ordem perceptual ou cognitiva. O jogo com as letras do nome, que constitui verdadeiras montagens textuais lidas ora como nome da criança, ora como escrita de outros textos, parece indicativo de um momento em que a criança desfaz 
Cadernos de Estudos Lingüísticos 47(1) e (2) - Jan./Dez. 2005

um bloco inicialmente escrito por um outro para delimitar seu lugar na linguagem escrita, ao mesmo tempo em que possibilita a abertura para o surgimento de outros significantes.

Dado o papel que a escrita do nome assume no percurso da relação da criança com a escrita, não podemos esquecer a historicidade em jogo em sua construção; uma história tecida de alienação aos significantes fornecidos por um outro e, só-depois, sua separação, configurando um movimento que possibilita a emergência da escrita de um sujeito, diríamos, em seu próprio nome.

\section{REFERÊNCIAS BIBLIOGRÁFICAS}

BOSCO, Z.R. (1999). No jogo dos significantes, a infância da letra. Dissertação de Mestrado em Lingüística, defendida no IEL/Unicamp e publicada em 2002 pela Campinas: Editora Pontes/FAPESP.

CALIL, E. (1995). Autoria - (E)feito de relações inconclusas. Tese de Doutorado em Lingüística. Campinas: IEL da Unicamp.

FERREIRO, E. (1987). Os processos construtivos de apropriação da escrita. In: FERREIRO, E. \& PALACIO, M. G. Os processos de leitura e escrita - novas perspectivas. Porto Alegre: Artes Médicas.

FERREIRO, E. \& TEBEROSKY, A. (1979). Psicogênese da língua escrita. Porto Alegre:Artes Médicas.

HILDRET, G. (1936). Developmental sequences in name writing. In: Child developmental, vol. 7, p. $291-303$.

LEMOS, C.T.G. (1992). Los procesos metafóricos y metonímicos como mecanismos de cambio. Substratum. Madrid, vol.1, n. 1, p. 103-120.

(1997) Native speaker's intuitions and a metalinguistics abilities: what do they have in common from the point of view of language acquisition?. Cadernos de Estudos Lingüísticos. Campinas: IEL da Unicamp, n. 33 , p. $5-14$.

(2001). Sobre fragmentos e holófrases. Anais do Encontro LEPSI. São Paulo: USP, p. 45-52.

LURÇAT, L. (1974). Études de l'acte graphique. Paris:Mouton

MILNER, J.C. (1987). O amor da língua. Porto Alegre: Artes Médicas.

MOTA, S.B.V. (1995). O quebra-cabeça - a instância da letra na aquisição da escrita. Tese de Doutorado em Psicologia da Educação. São Paulo: PUC.

PEREIRA DE CASTRO, M.F. (1998). Língua Materna: palavra e silêncio na aquisição da linguagem. In: JUNQUEIRA FILHO, L.C.U., Silêncios e luzes: sobre a experiência psíquica do vazio e da forma. São Paulo: Casa do Psicólogo.

(2003). Apontamentos sobre o corpo da linguagem. In: LEITE, N.V.A . (org.) CorpoLinguagem: gestos e afetos. Campinas: FAEP/Mercado de letras.

SAUSSURE, F. (1974). Curso de Lingüística Geral. São Paulo: Cultrix

STAROBINSKI, J. (1974). As palavras sob as palavras: os anagramas de Ferdinand de Saussure. São Paulo: Perspectiva.

TEBEROSKY, A. (1991). Aprendendo a escrever. São Paulo:Ática. 